\title{
FAILURE EXAMINATION OF DISC HEADER WORKPOINTS USING CAE-SYSTEM APM WINMACHINE
}

Alexey Slobodyuk, Sergey Strebkov, Andrey Bondarev Belgorod State Agricultural University named after V. Gorin, Russia asp122@yandex.ru, serwastr@gmail.com, av.bondarev@gmail.com

\begin{abstract}
The scientific work is devoted to search for failure reasons of disk workpoints applying CAE-system APM WinMachine. The purpose of the research is to find the causes of sudden destructions of the disk header's spring tines and to search for constructive solutions for prevention of the detected failures. The problem is solved by constructing the finite element model of the structure's problem element and analyzing its strain-stress state under various loading conditions using the module Structure 3D CAE-system APM WinMachine and comparing these results with the analysis of full-scale samples. In order to determine the geometric parameters of the structure input elements, as well as to adequately model the fixation of the interested part and the correct load application a 3D model of the assembly unit can be used. As a result of our calculations it is found that the reason for sudden destruction of the disk header's spring tines is the resonance with the torsional vibrations of the workpoint spring tine at the operating speeds of the unit. For finding engineering solutions to prevent the resonance of the elastic tine, a simplified plate- beam model of the elastic tine has been constructed, in which the loads of active force and structural mass influence are taken into account. In the number of experiments several solutions were made to change the eigenfrequencies of the obtained oscillatory system and a simple and effective solution for resonance preventing was proposed without significant design modification for farms using this disk header. For the manufacturer the improved design has been developed, which eliminates resonant phenomena and increases the workpoint reliability.
\end{abstract}

Keywords: failures, sudden destruction, CAE system, finite element model.

\section{Introduction}

Modern resource-saving, low-cost technologies for cultivating and harvesting agricultural crops widely use operations done by disk implements $[1 ; 2]$, built according to the power scheme with workshop spring tines.

Exploitation of the prototype of a two-row trailed disk aggregate has shown good workmanship and strong characteristics: however, when the machine moves in the working position at speeds close to the maximum one, specified by the manufacturer $\left(15-17 \mathrm{~km} \cdot \mathrm{h}^{-1}\right)[3 ; 4]$, destruction of spring tines can be observed, Fig. 1.

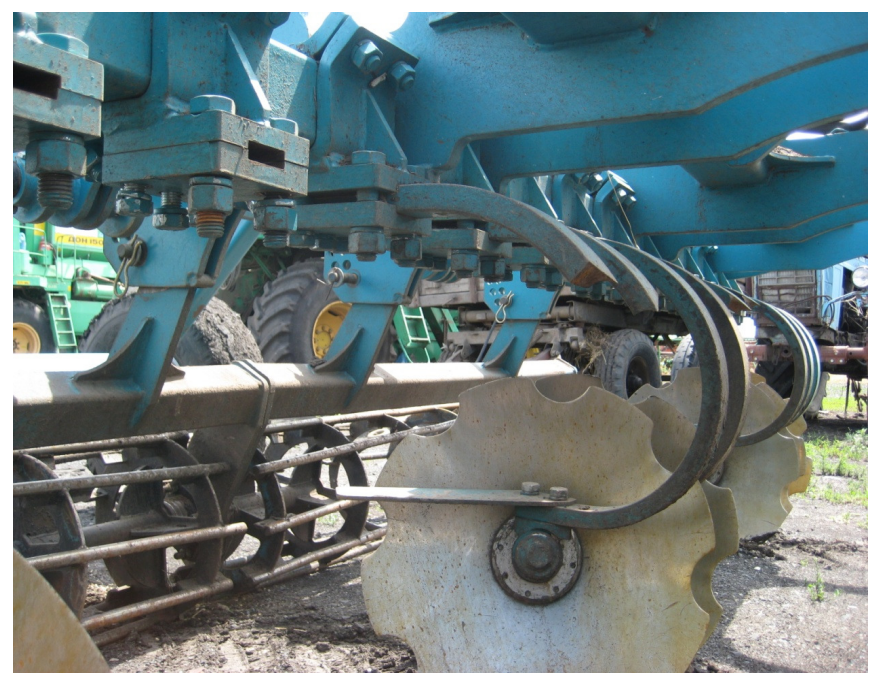

Fig. 1. Destruction of disk spring tines

And it is impossible to find any regularity neither in series, in which the destruction takes place, nor in the operating time.

The only regularity, which could be truly established, was the one concerned with the breaking point. Destruction occurred at the distance of $120-250 \mathrm{~mm}$ from the attaching point of the spring tine to the machine frame. 
Thus, the main research task is to determine the cause of the sudden destruction of the spring tines of the disk header, taking place in operation and to search for constructive solutions for prevention of the detected failures.

\section{Materials and methods}

The solution task was done in the following order:

- finite-element model of the workpoint tines was constructed and a number of numerical experiments were done to determine its stress-strain state under various loading regimes;

- based on a comparison of these research results with the natural sample analysis - the cause of the structure destruction was found;

- simplified plate- beam model of the elastic tine was developed, which takes into account the loads of active forces and the structural masses influence, and according to its dynamic supposes constructive decisions for prevention of the detected failures.

Determination of the causes of sudden destruction of the main power element of the disk workpoint - spring tine - was carried out based on the analysis of the stress-strain state of this part by the finite element method in the Structure 3D module of the APM WinMachine package [5].

Based on the full-scale measurements, as well as the manufacture's technical documentation, in KOMPAS 3D we have built 3D models of all parts and modeled the whole assembly unit (Fig. 2).

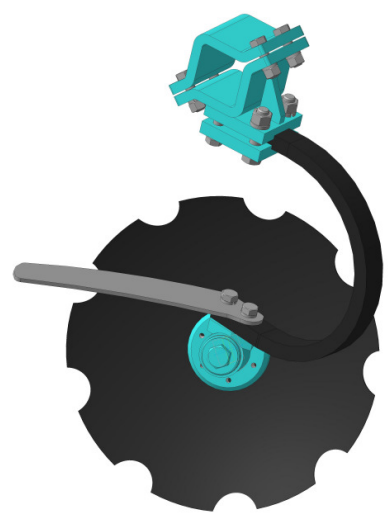

Fig. 2. Assembly unit 3D model

The assembly unit model is important not only from the point of view of its part geometry, but also to adequately model the fixed part and the correct application of load.

The object under study is a spring tine, which is a half of the spiral turn with a step of $90 \mathrm{~mm}$ with a diameter of $460 \mathrm{~mm}$, wound from the strip 50HGFA with section 50x30 mm. Straight sections begin and end the spiral turn: with a length of $170 \mathrm{~mm}$ for attachment to the frame through the connecting unit and with a length of $100 \mathrm{~mm}$ with two holes, in which the disk unit is attached.

For calculation, first of all, it is necessary to construct finite element mesh of the part [6]. This operation was done in the APM Studio APE WinMachine CAE-system using the 3D model of our object (Fig. 3).

The final structure is quite regular and the parts have 8 layers of thickness and there is no collapsing of small gills. This allows to expect a good convergence and sufficient accuracy of the model calculation [5; 7].

The design model was formed in the APM Structure 3D module. The research of construction of the tine attachment point to the machine frame has found that an adequate fixing model is an "anchorage" fixation. Thus, the fixation of the anchorage type was done for all nodes of the finite element mesh, located on the upper and lower edges of the straight part at the length of $170 \mathrm{~mm}$ (Fig. 4). We modelled the loading from the disk node point by the distributed load along the surface bottom of the straight section with two holes, in which the cutting unit is attached (Fig. 4).

The amount of effort applied to each node is determined from the total traction resistance of the disc header, which was found in traction tests and the vertical load represents the whole machine 
gravity spread out over all workpoints. Thus, the horizontal force to the tine should be $3500 \mathrm{~N}$ and the vertical force should be $900 \mathrm{~N}$.

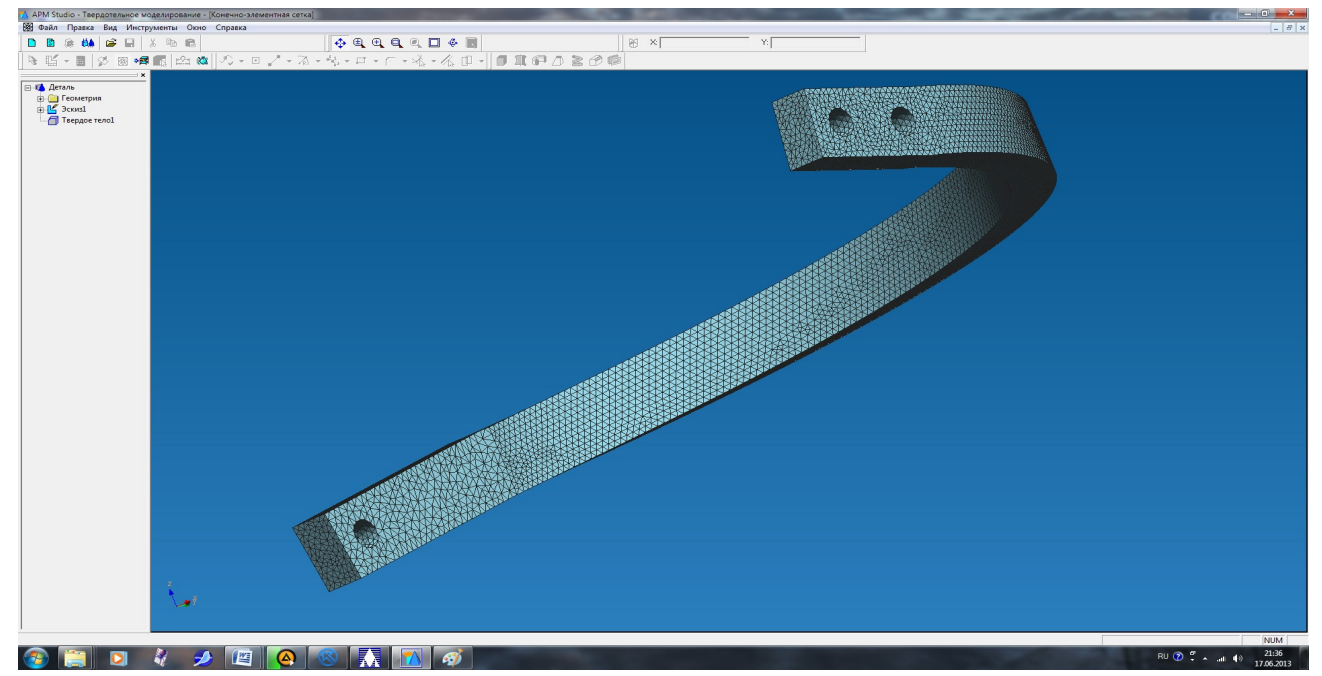

Fig. 3. Finite element grid of spring rack

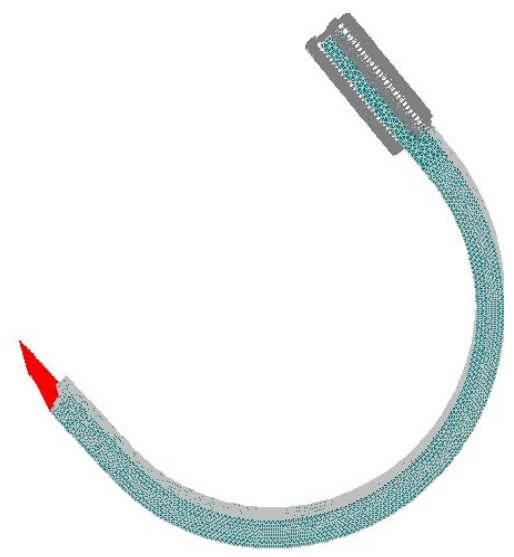

Fig. 4. Design model

\section{Results and discussion}

In the Structure 3D Module of CAE-system APM WinMachine we have done a static calculation, stability calculation and determination of the structure eigenfrequency. As a result, we have got strainstress state of the tine (Fig. 5), which analysis showed that the construction design has a sufficient static strength (stock ratio 4.5) and endurance limit (endurance factor indicator is 2.3).

Therein the zone of maximum stresses is localized, where destruction occurs most often, but the nature of destruction of full-scale samples is definitely not static, so static strength exhaustion is not the cause of destruction.

Prop distortion demonstrates signs of fatigue failure (Fig. 6) [8], but the nature of this crack is not answerable to the tine loading scheme; so the obtained safety factor is considered as an adequate one. In this case the cause of structural failure may be technological defects or material defects.

The manufacturer's specialists have done research of the chemical composition and microhardness parameters along the cross section of the elastic tine in the workpoint. The obtained results show that the chemical composition of the tine material corresponds to the specified by the supplier and it is typical for steel - 50HGFA. It was also established that the technological process of deformation and heat treatment is fully maintained. 


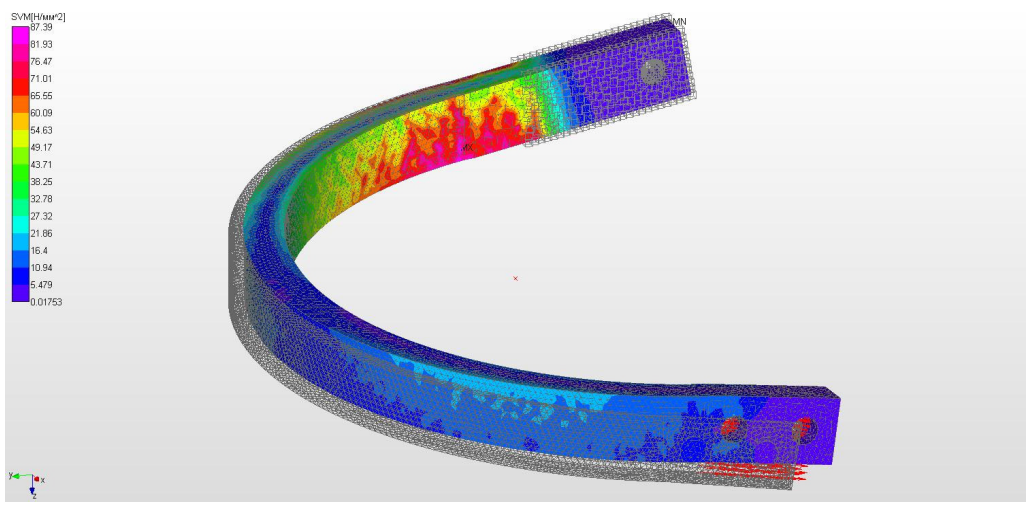

Fig. 5. Stress distribution in tine of workpoint

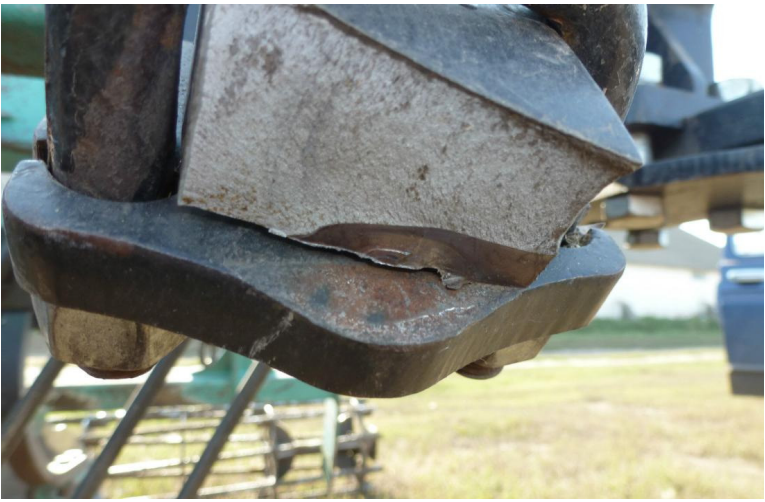

Fig. 6. Prop distortion

Thus, there are not any mistakes in the design and in manufacture of the elastic tine of the workpoint and this node should provide strength, stiffness and stability.

When analyzing the natural frequencies of the elastic tine, it was found that the first and second frequencies of the tine $(47 \mathrm{~Hz}$ and $53 \mathrm{~Hz})$ are relatively small. Taking into account the fact that a massive disk is fixed to the elastic tine, one can expect that the natural frequencies for whole workpoint will be even lower. Therefore, we made a hypothesis that the destruction of the elastic tine occurs as a result of resonance falling.

For checking the proposed hypothesis we have corrected the model taking into account the mass concentrated at the end of the tine in the form of a disk, hub, hull, etc.

For the new design model the mass-centering characteristics of the disk assembly were determined and a plate was added into the finite-element model, which mass is equal to the mass of the disk assembly $(22.4 \mathrm{~kg})$, and the dimensions correspond to the mass distribution along the lower edge of the elastic tine taking into account the disk mounting scheme. At the same time, the fixing parameters and loading of the tine were similar for the tine model without load.

For this corrected model the static calculation and determination of the structure's own frequencies were done. As a result the structure stress-strain state was obtained, which under analyzing demonstrates that the construction design provides a sufficient static strength (safety factor at proof stress in tine is 4.03) and endurance limit (indicator of endurance limit is 1.92).

The structure eigenfrequency (Table 1), as expected, has decreased.

Table 1

Eigenfrequency of the model with the load

\begin{tabular}{|c|c|c|}
\hline Frequency No. & ${\text { Frequency, } \mathbf{~ r a d} \cdot \mathbf{s}^{-1}}^{\mathbf{1}}$ & Frequency $\mathbf{~ H z}$ \\
\hline 1 & 98.4 & 15.7 \\
\hline 2 & 121.8 & 19.4 \\
\hline 3 & 329.7 & 52.5 \\
\hline 4 & 780.6 & 124.2 \\
\hline
\end{tabular}


In order to check the resonance hypothesis it is necessary to analyze the possible sources of the disturbing force and to estimate their frequency characteristics.

We calculated the frequency of disturbing effects on the workpoint tine, caused by rolling over the hard surface of the cut-out disk.

The workpoint of the disk header is a cut-out disc with a diameter of $600 \mathrm{~mm}$ (Fig. 2) with a number of cuts $z=9$.

Moving at a speed $V, \mathrm{~km} \cdot \mathrm{h}^{-1}$, the disk rotation speed $n, \mathrm{r} \cdot \mathrm{s}^{-1}$ is

$$
n=\frac{k_{V} V}{L},
$$

where $k_{v}=277.778-$ conversion factor associated with the dimensions of the quantities, which are put into the formula;

$L=1885 \mathrm{~mm}-$ arc length of the disk circle.

For each disk turn the cutouts produce $\mathrm{z}$ influences, therefore, during moving the frequency of the perturbation actions $v$ is

$$
v=n \cdot z=\frac{k_{V} V}{L} \cdot z
$$

or combining constants

$$
v=k_{\lambda} \cdot V .
$$

With the available disk parameters we finally obtain the dependence of the frequency of perturbation actions $v, \mathrm{~Hz}$ from the aggregate motion speed $\mathrm{V}, \mathrm{km} / \mathrm{h}$ in the form

$$
v=1.326 \cdot V \text {. }
$$

Comparing the obtained data of natural frequencies (Table 1) we made a conclusion that the most likely structure in resonance occurs at the second natural frequency $\mathrm{v}=19,4 \mathrm{~Hz}$, which corresponds to the aggregate motion speed $V=14.6 \mathrm{~km} \cdot \mathrm{h}^{-1}$.

The second natural frequency corresponds to the torsional vibrations of the workpoint around the axis, which passes through the tine`s mounting portion (Fig. 7).

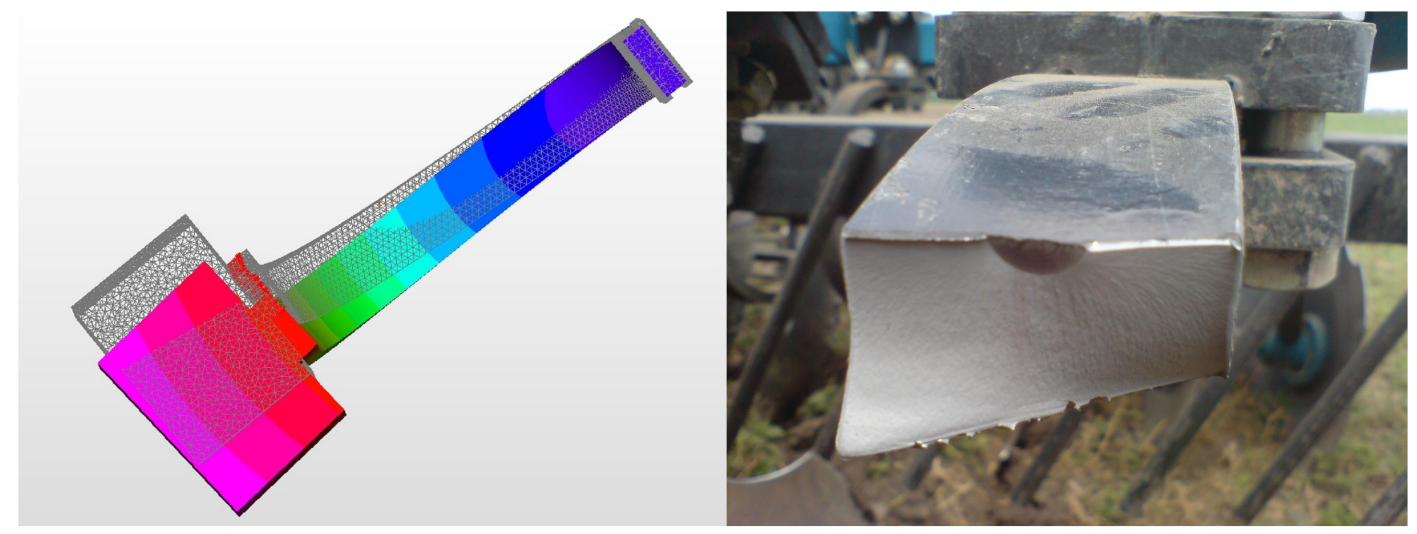

Fig. 7. Form of spring tine and breaking point

The research of prop distortion (Fig. 7) shows that the development of a fatigue crack begins in the middle of a long face of a rectangular cross-section, i.e. it occurs in the action zone of maximum tangential stresses, which fully corresponds to the fatigue fracture in torsion [9]. The evaluation of other broken tines (Fig. 1) confirms our hypothesis: because most of the distortion sites are inclined at an angle of $45^{\circ}$, which is also typical for torsional fracture [10].

As it is established that the destruction occurs due to elastic tine into resonance, the main solution is to decrease the natural frequencies of the workpoint structure and to shift the operating frequency range to the second post-resonance regime [11]. The most effective reducing measure of the structures' natural frequencies is reduced mass increasing [12; 13]. 
Therefore, we have researched the increase effect in mass (for example, additional load adding) of the elastic tine on the structure natural frequencies (Fig. 8).

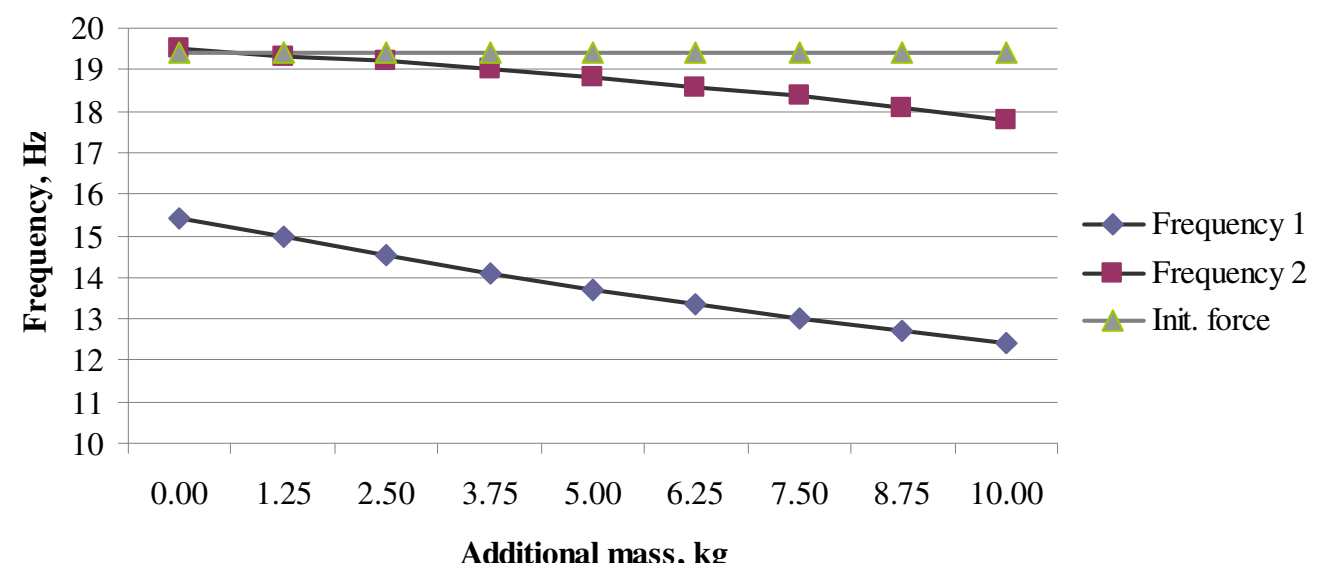

Fig. 8. Natural frequencies dependence on additional mass (operating speed $14.5 \mathrm{~km} \cdot \mathrm{h}^{-1}$ )

According to the research results for resonance prevention it is recommended to put additional mass of $8.5-9.0 \mathrm{~kg}$ on the disk body and simultaneously put the lower limit of the aggregate's operating speed at least 14.5 and not more than $15.5 \mathrm{~km} \cdot \mathrm{h}^{-1}$.

One can reduce the structure natural frequency by decreasing the unit stiffness [14]. Therefore, the easiest solution is to change the mounting scheme of the elastic tine with an additional spring linkage; in other words, to achieve the effect that is necessary to get rid of anchorage by adding two additional elastic supports and simultaneously releasing two rotational degrees of freedom in the damaged tine plane.

Numerical experiments of the proposed scheme have found that optimal stiffness of supports is in the range of $1300-1600 \mathrm{~N} \cdot \mathrm{mm}^{-1}$.

In CAD-system KOMPAS 3D the design of anchors of the disk workpoint was made, which prevents resonant phenomena (Fig. 9). At the same time, tray type springs are used as elastic supports, which provide the required stiffness value with minimal displacements.

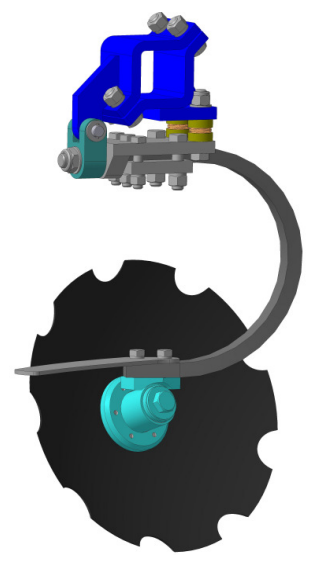

Fig. 9. Developed design

\section{Conclusions}

The conducted researches have found that the reason for sudden destruction of the spring tines of the disc header is resonance at the operation speed of about $15 \mathrm{~km} \cdot \mathrm{h}^{-1}$.

In a number of numerical experiments several solutions have been analyzed for natural frequencies changing of the obtained oscillating system and a simple and effective solution proposed for resonance preventing without significant design modification for farms operating the disk header.

For the manufacturer the improved design has been developed, which eliminates resonant phenomena and increases the workpoint reliability. 


\section{References}

[1] Современные энергосберегающие технологии обработки почвы (Modern energy-saving technologies of soil cultivation) [online] [15.01.2018]. Available at: http://urozhaynagryadka.narod.ru/energosber.technologii.htm (In Russian)

[2] Технология «нулевой» обработки почвы (The technology of "zero" tillage) [online]. [15.01.2018]. Available at: http://opyt.t30p.ru/post/leopoliss-No-Till-eto-znachit-bez-vspashkiTehnologiya-nulevoi-obrabotki-pochvi.aspx (In Russian)

[3] Passport of the Disc header "Dominanta".

[4] "Promagro" - advanced technologies of agribusiness [online]. [15.01.2018]. Available at: http://promagro.su/

[5] Замрий А. А. Проектирование и расчет методом конечных элементов в среде АРМ Structure3D (Zamryi A.A.. Design and calculation by the Finite Element Method in the APM Structure3D). Moscow: Publishing House of the APM, 2010, 376 p. (In Russian)

[6] Bhavikatti S.S. Finite Element Analysis. New Delhi: New Age International, 2005, 347 p.

[7] Baker A.J. Finite Elements: Computational Engineering Sciences. Chichester: John Wiley \& Sons, 2012, $288 \mathrm{p}$.

[8] Трощенко В.T. Сопротивление усталости металлов и сплавов. Справочник (Troschenko V.T. Resistance fatigue of metals and alloys. Reference book.). Kiev, Naukova Dumka, 1987, 1303 p. (In Russian)

[9] Березин И.Я., Чернявский О.Ф. Сопротивление материалов. Усталостное разрушение металлов и расчеты на прочность и долговечность при переменных напряжениях (Materials resistance. Fatigue failure of metals and strength and durability calculations under fluctuating stress). Chelyabinsk: Izd. SUSU, 2002, 544 p. (In Russian)

[10]Феодосьев В.И. Сопротивление материалов (Feodosiev V.I. Materials resistance). Moscow, Publisher MSTU, 1999. 589 p. (In Russian)

[11] Артоболевский И.И. Теория механизмов и машин (Artobolevsky I.I. Mechanisms and machines theory). Moscow, Alliance, 2011, 640 p. (In Russian)

[12] Лапин А.А. Колебания и вибрации в машинах (Lapin A.A. Vibrations and power fluctuations in machines). Moscow, Mashgiz, 1953, 95 p. (In Russian)

[13]Lees A.W. Vibration Problems in Machines: Diagnosis and Resolution. New York: CRC Press, Taylor \& Francis Group, 2016, XVI, 321 p.

[14]Вульфсон И.И. Динамика механизмов с учетом упругости звеньев (Mechanisms dynamics taking into account the units' elasticity).Leningrad, Publishing House of the LPI, 1984. 79 p. (In Russian) 